E3S Web of Conferences 1, 39008 (2013)

DOI: $10.1051 / \mathrm{e} 3 \operatorname{sconf} / 20130139008$

(C) Owned by the authors, published by EDP Sciences, 2013

\title{
Speciation of Six-Arsenic Species of Rice in Korea by HPLC/ICPMS
}

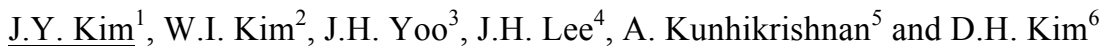 \\ ${ }^{1}$ Department of Agro-food Safety, National Academy of Agricultural Science, Rural Development Administration, \\ Republic Korea, jykim98@korea.kr \\ ${ }^{2}$ Department of Agro-food Safety, National Academy of Agricultural Science, Rural Development Administration, \\ Republic Korea, wikim721@korea.kr \\ ${ }^{3}$ Department of Agro-food Safety, National Academy of Agricultural Science, Rural Development Administration, \\ Republic Korea, idisryu@korea.kr \\ ${ }^{4}$ Department of Agro-food Safety, National Academy of Agricultural Science, Rural Development Administration, \\ Republic Korea, jhlee76@korea.kr \\ ${ }^{5}$ Department of Agro-food Safety, National Academy of Agricultural Science, Rural Development Administration, \\ Republic Korea, Anudpak@gmail.com \\ ${ }^{6}$ Department of Agro-food Safety, National Academy of Agricultural Science, Rural Development Administration, \\ Republic Korea, kdho@korea.kr
}

\begin{abstract}
Determination of arsenic (As) speciation in rice is necessary because inorganic As species are more toxic than organic As. Arsenic levels of rice in Korea were determined by microwave extraction and High Performance Liquid Chromatography coupled with Inductively Coupled Plasma-Mass Spectrometry. The extraction method showed a high recovery and low Limit of Detection (LOD) and Limit of Quantitation (LOQ). Most of the As species in rice were noticed to be inorganic [Arsenite (As ${ }^{\mathrm{III}}$ ), Dimethylarsinic acid (DMA)]. The percentage of inorganic As/total As is $69.01 \%$ (36.40-87.86 \%). Arsenite and DMA were the major compounds in rice in Korea when compare to U.S. rice. The order and percentage of As species showed were $\operatorname{As}^{\text {III }}(56-70 \%)>\operatorname{DMA}(23-38 \%)>\operatorname{As}^{\mathrm{V}}(5 \%)>\operatorname{MMA}(1 \%)$.
\end{abstract}

Key words: Speciation, Arsenic species, HPLC/ICPMS, Rice

\section{Introduction}

Arsenic exist in forms of various chemical species (Maeda. S, 1994). In-organic arsenic species (arsenate $\left(A s^{\mathrm{V}}\right.$ ) and arsenite (As $\left.{ }^{\mathrm{III}}\right)$ ) have been classified as carcinogenic and the methylated form, monomethylarsonic acid (MMA) and dimethylarsinic acid (DMA) have been identified as cancer promoters. It is believed that arsenobetaine (AB) and arsenocholine (AC) are non-toxic (Ronkart et al., 2007). Thus, it is important to separate and measure the chemical forms of As for accurate risk assessment. Arsenic speciation analysis of agricultural products, biological and environmental samples have been studied extensively (Nakamura et al., 2008). Most of As-speciation analytical methods are based on chromatographic separation techniques such as High performance Liquid Chromatography (HPLC) or Capillary Electrophoresis (CE) coupled with Atomic Absorption Spectrometry (AAS) and, Inductively Coupled Plasma-Mass Spectrometry (ICP-MS). The present study was to determine the analytical method of As-species and to provide the percentage of inorganic As/total As and accurate information of human health risk assessment.

\section{Materials and Methods}

Rice samples were collected from the markets (polished rice) and mining impacted areas (mining rice) in Korea. All the samples were homogenized by grinding. The contents of total As were measured using ICP/MS after acid digestion with microwave-assisted apparatus. Arsenic species in rice samples were extracted with microwave-assisted $1 \%$ nitric acid (Foster et al., 2007). Around $0.1 \mathrm{~g}$ rice samples was weighed into teflon digest tube and digested with $10 \mathrm{~mL}$ of $1 \%$ nitric acid at $80{ }^{\circ} \mathrm{C}$, for $30 \mathrm{~min}$. Samples were cooled to room temperature and centrifuged at $4500 \mathrm{rpm}$ for $10 \mathrm{~min}$. The supernatant was filtered and kept at $4{ }^{\circ} \mathrm{C}$ until analysis. For quality control, the rice flour CRM, NMIJ-7513a and NIST SRM $1568 \mathrm{a}$ were also analyzed. Arsenic speciation was 
quantified by HPLC-ICP/MS using PRP-X100 anion exchange column (250 $\mathrm{mm} \times 4.1 \mathrm{~mm}$ i.d., $10 \mathrm{um})$. The gradient mobile phase was $2 \mathrm{mM}$ ammonium carbonate adjusted to $\mathrm{pH} 8.0$ and $20 \mathrm{mM}$ ammonium nitrate and, ammonium phosphate adjusted to $\mathrm{pH} 9.0$.

A b u n d a n c e

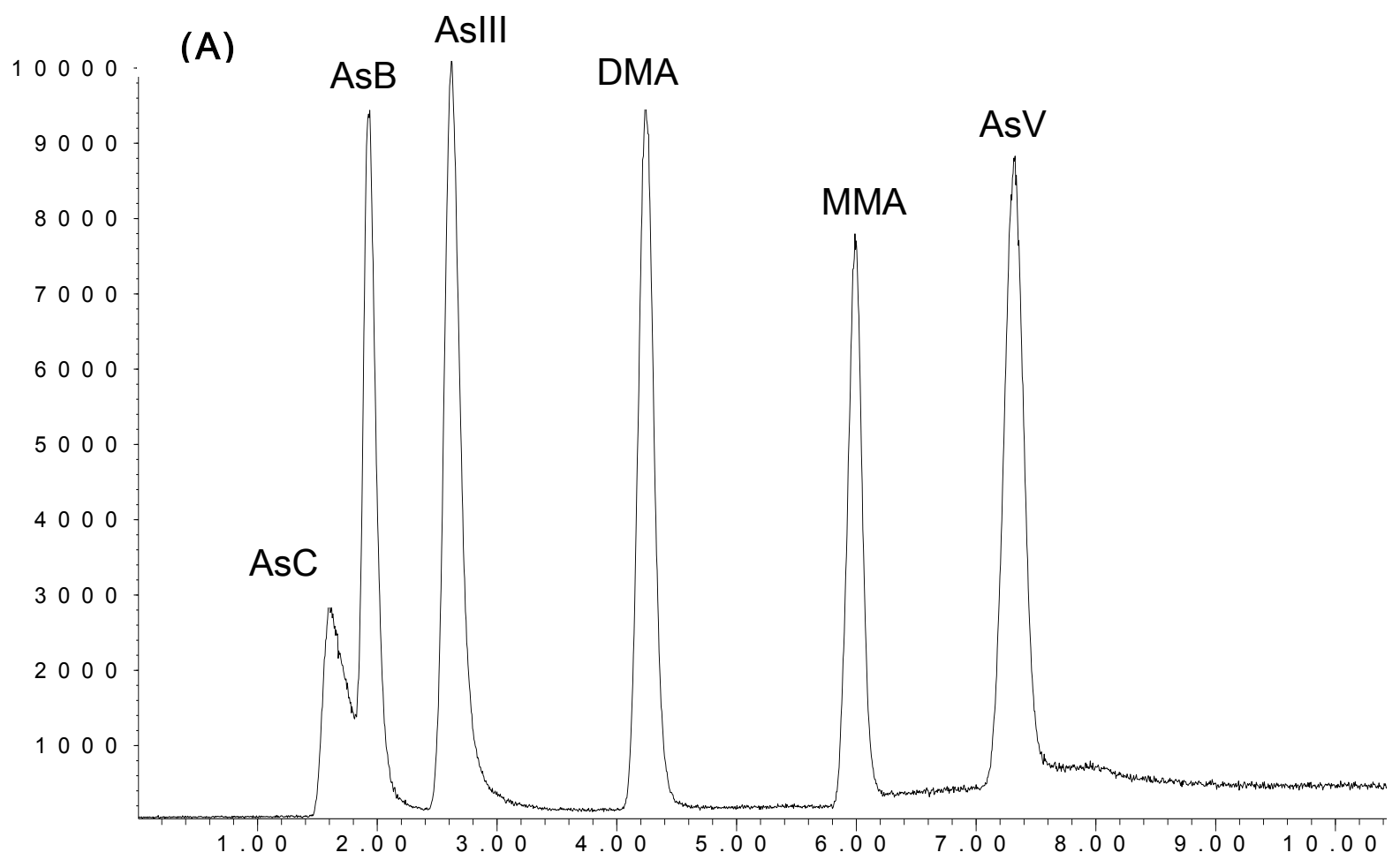

Tim e - - >

Abundance

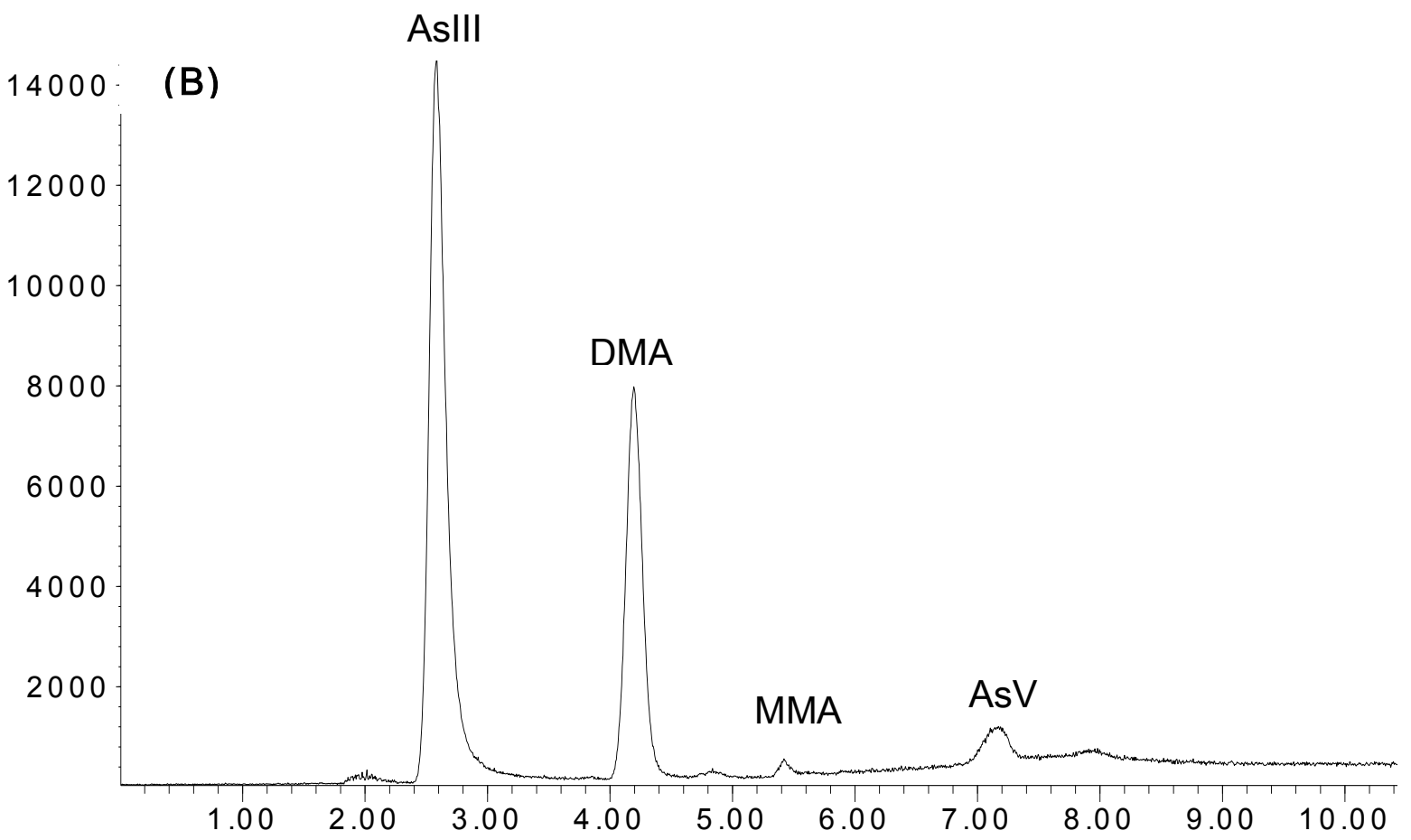

Time-->

Fig. 1. HPLC-ICP/MS chromatogram for As speciation in ((A) standard, (B) rice sample) 


\section{Results and Discussion}

The HPLC-ICP/MS chromatograms of the speciation analysis of As in rice sample and standard solution are shown in Fig. 1. The order of major compounds in rice samples were As ${ }^{\text {III }}>$ DMA $>\mathrm{AS}^{\mathrm{V}}>\mathrm{MMA}$. The accuracy and precision of the method were evaluated on the recoveries of CRM and fortified samples. The recoveries of fortified rice $(50 \mathrm{ng} / \mathrm{g}$ ) were 96.80-111.02\%. Total As and As species results are reported in Table 1 . The mean concentration of inorganic $\mathrm{As}\left(\mathrm{As}^{\mathrm{III}}, \mathrm{AS}^{\mathrm{V}}\right)$ was $0.14 \pm 0.03$ $\mathrm{mg} / \mathrm{kg}$ in mining rice and $0.08 \pm 0.03 \mathrm{mg} / \mathrm{kg}$ in polished rice. The percentage of inorganic As based on total As was $36.40-87.86 \%$ in mining and polished rice.

Table 1. Total arsenic and speciation results in rice samples $(\mathrm{mg} / \mathrm{kg})$

\begin{tabular}{cccccc}
\hline $\begin{array}{c}\text { Sam } \\
\text { ples }\end{array}$ & $\mathrm{As}^{\mathrm{III}}$ & DMA & MMA & $\mathrm{As} \mathrm{V}^{\mathrm{V}}$ & $\begin{array}{c}\text { InorganicAs } \\
\text { /Total As \%) }\end{array}$ \\
\hline $\begin{array}{c}\text { Mining } \\
\text { rice } \\
(\mathrm{n}=31)\end{array}$ & 0.12 & 0.08 & 0.003 & 0.01 & 61.34 \\
$(56 \%)$ & $(38 \%)$ & $(1 \%)$ & $(5 \%)$ & $(36.40 \sim 79.93)$ \\
\hline $\begin{array}{c}\text { Polishe } \\
\text { d rice }\end{array}$ & 0.08 & 0.03 & 0.002 & 0.005 & $\begin{array}{c}76.94 \\
(\mathrm{n}=30)\end{array}$ \\
\hline
\end{tabular}

The concentration of inorganic As $\left(\mathrm{As}^{\mathrm{III}}, \mathrm{As}^{\mathrm{V}}\right)$ increased linearly $\left(\mathrm{R}^{2}=0.70\right)$ with increasing total As concentration. Yamily (2008) reported that DMA increased linearly with increasing total As in U.S. rice. So, we recognized that rice in Korea was an inorganic As type, whereas rice from U.S. with a DMA type.

\section{Conclusion}

The method of As speciation by HPLC-ICPMS was developed which allowed the simultaneous separation by six As species. The results indicated that microwave-assisted extraction provided good extraction efficiency. The LOD of As-speciation method was $0.1-0.5 \mathrm{ug} / \mathrm{kg}$. Based on As speciation in rice, $\mathrm{As}{ }^{\mathrm{III}}$ and DMA were the major compounds and $\mathrm{AsC}$ and $\mathrm{AsB}$ were not found. The order and percentage of As species revealed in this study were As ${ }^{\mathrm{III}}(56-70 \%)$ $>\operatorname{DMA}(23-38 \%)>\operatorname{As}^{\mathrm{V}}(5 \%)>\operatorname{MMA}(1 \%)$.

\section{Acknowledgements}

The authors would like to thank the financial support from RDA(2012 Project-PJ008650)

\section{References}

Maeda S, 1994. Safety and Environmental Effects, The Chemistry of Organic Arsenic, Antimony and Bismuth Compounds. John Wiley \&Sons, New York, 725-759.

Ronkart SN, Laurent V, Carbonnelle P, Mabon N, Copin A, Barthelemy JP. Speciation of five arsenic species in different kind of water by HPLC-ICP-MS. Chemosphere 2007; 66; 738-745.

Nakamura Y, Narukawa T, Yoshinage J. Cancer risk to Japanese population from the consumption of inorganic arsenic in cooked hijiki. J.Agric Food Chem. 2008; 56; 2536-2540.

Foster S, Mahera W, Krikow F, Apte S. A microwave-assisted sequential extraction of water and dilute acid soluble arsenic species from marine plant and animal tisuues. Talanta 2007; 71; 537-549.

Yamily JZ, Russell G, Hakan G, John MD. Arsenic in Rice: II. Arsenic Speciation in USA Grain and Implications for Human Health. Environ. Sci. Technol. 2008; 42; 3861-3866. 